\title{
A Compact Vivaldi Shaped Partially Dielectric Loaded TEM Horn Antenna for UWB Communication
}

\author{
Mustafa İlarslan, ${ }^{1}$ A. Serdar Türk, ${ }^{1}$ Salih Demirel, ${ }^{1}$ \\ M. Emre Aydemir, ${ }^{2}$ and A. Kenan Keskin ${ }^{1}$ \\ ${ }^{1}$ Electronics \& Communication Engineering Department, Yildiz Technical University, Esenler, 34220 Istanbul, Turkey \\ ${ }^{2}$ Aeronautics \& Space Technologies Institute, Turkish Air Force Academy, Yesilyurt, 34149 Istanbul, Turkey \\ Correspondence should be addressed to A. Serdar Türk; asturk@yildiz.edu.tr
}

Received 2 May 2014; Revised 21 July 2014; Accepted 1 August 2014; Published 10 September 2014

Academic Editor: Li Wenxing

Copyright (c) 2014 Mustafa İlarslan et al. This is an open access article distributed under the Creative Commons Attribution License, which permits unrestricted use, distribution, and reproduction in any medium, provided the original work is properly cited.

\begin{abstract}
Ultrawideband (UWB) antennas are of huge demand and Vivaldi antennas as well as the TEM horn antennas are good candidates for UWB applications as they both have relatively simple geometry and high gain over a wide bandwidth. The aim of this study is to design a compact antenna that achieves maximum gain over a bandwidth between 1.5 and $10.6 \mathrm{GHz}$ while minimizing its size. The idea is to make use of combined respective advantages of Vivaldi and TEM horn antennas to achieve the desired goals by shaping the TEM horn antenna to look like a Vivaldi antenna. The antenna structure is modified by a dielectric load in the center to increase the gain bandwidth. It is placed in a surrounding box made of PEC material to reduce the undesired side lobes and to obtain more directive radiation pattern. The simulations are performed by using the CST STUDIO SUITE electromagnetic (EM) simulation software and they are later verified by the actual measurements. The Vivaldi shaped partially dielectric loaded (VS-PDL) TEM horn antenna is proposed as a compact UWB antenna for systems using the newly established UWB band and also for the communication systems of popular bands like ISM, Wi-Fi, and GSM.
\end{abstract}

\section{Introduction}

Even though the idea was older, UWB technology has become popular starting from the late 1960s because of its use in the form of impulse radar in military area. Its development even accelerated after FCC had approved the UWB technology for commercial use in 2002 [1].

UWB technologies have been used increasingly for highspeed RF wireless communication, high power RF jamming, and high-resolution impulse radar systems as they have a number of advantages over traditional narrowband systems like low complexity, low cost, and improved detection, ranging, and target resolution performances $[1,2]$.

UWB antennas are obviously a vital part of these systems as they are closely linked to the system performance. They are basically needed to have maximum gain over a specified wide bandwidth. Other antenna features can be considered as application specific.
In this study, our purpose is to design a compact UWB antenna with a gain level close to $10 \mathrm{dBi}$ over the bandwidth starting from $1.5 \mathrm{GHz}$ up to $10.6 \mathrm{GHz}$. In the analog RF frontend, a high relative bandwidth and not necessarily a high absolute bandwidth poses new challenges to the RF system design. We therefore concentrate on this band where a large variety of system concepts are under investigation worldwide [1].

This paper is composed of four sections in total; following the introduction, antenna design is described in Section 2, simulation and measurement results are given in Section 3, and finally Section 4 is for the conclusions.

\section{Antenna Design}

This paper is all about the design and development of a compact UWB antenna based upon Vivaldi and TEM horn antennas both of which have respective advantages for the 


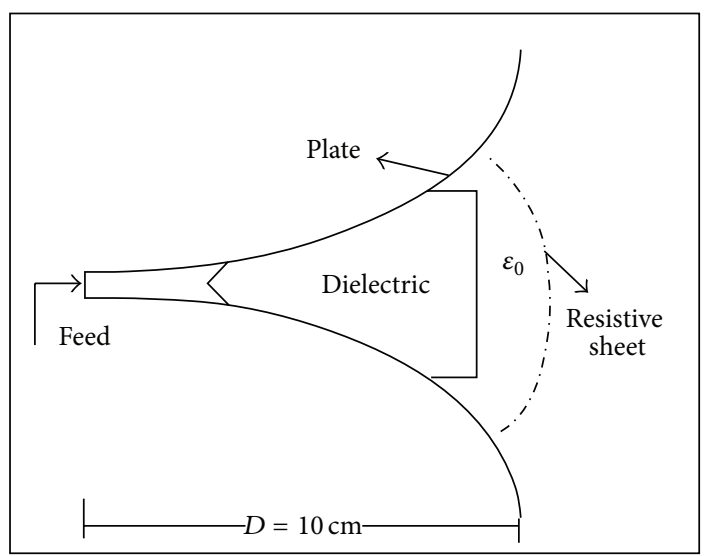

FIgURE 1: Vivaldi Shaped TEM horn antenna (PDVA10) [7].

possible UWB applications as mentioned above. The idea is to make use of these combined respective advantages of Vivaldi antennas and TEM horn antennas to achieve the desired goals by shaping the TEM horn antenna to look like a Vivaldi antenna.

The antenna structure is modified by partially loading it in the center with a dielectric Teflon material of $\varepsilon r=2.1$ in order to decrease the lower frequency limit and by doing so increasing the frequency range of the antenna [3]. The dielectric filling or partial dielectric loading techniques are employed commonly as mentioned in the literature [4-6] to broaden the operational band up to twice and improve the directivity (gain) performance. It is noted that the partial dielectric loading operation should not result in altering the physical dimensions of the antenna (including its weight) in a negative manner [6].

The partially dielectric loaded TEM (PDTEM) horn, its Vivaldi shaped version (PDVA), and array combinations have been introduced by Turk as efficient UWB impulse radiators for GPR (Ground Penetrating Radar) operation to obtain UWB characteristics from $150 \mathrm{MHz}$ to $10 \mathrm{GHz}[4,7,8]$.

As a specific example, the partially dielectric-loaded Vivaldi antenna (PDVA) which yields ultrawide band antenna characteristics from $400 \mathrm{MHz}$ to $10 \mathrm{GHz}$ was introduced and referred to as PDVA10 (meaning an aperture depth length of $10 \mathrm{~cm}$ ) in [7] as given in Figure 1. It had a positive gain over the specified bandwidth which came close to $10 \mathrm{dBi}$ at higher frequencies. It was designed for multisensor adaptive-impulse GPR operation and its performance was promising when compared to the regular (no dielectric loading) TEM horn and Vivaldi antennas.

However, it has the disadvantage of having a large size. Our purpose herein is to improve that design to make it smaller (compact) for some possible applications in UWB communication systems as it covers whole popular wireless frequency bands. To make it compact, the height of the antenna is reduced up to $8 \mathrm{~cm}$ to cancel the lower bands of the spectrum which were needed for GPR operations and the depth of the $E$-plane (flared vertically) horn antenna aperture has been changed from $8 \mathrm{~cm}$ down to $3 \mathrm{~cm}$ as the primary

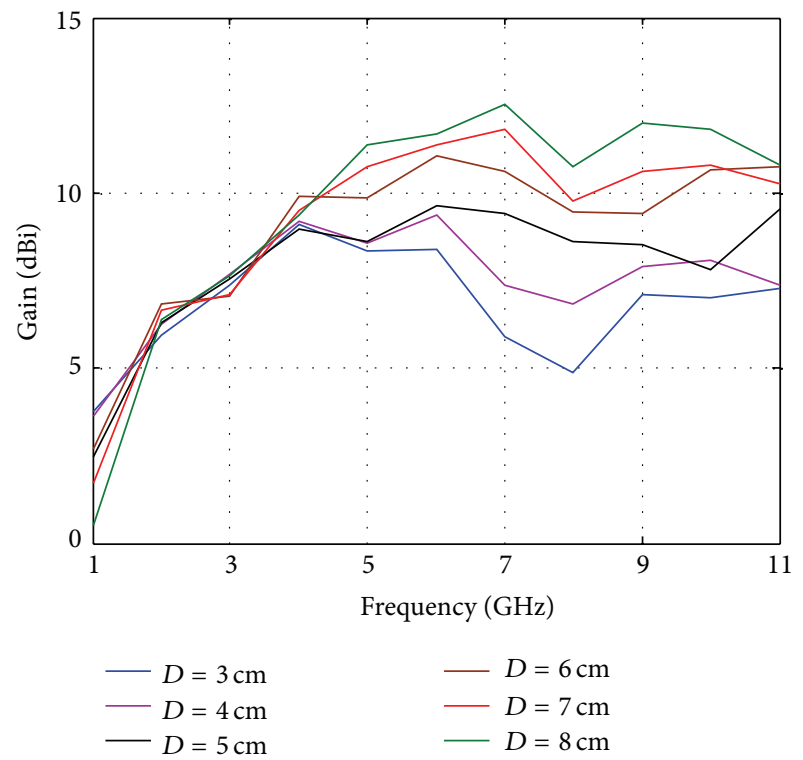

FIGURE 2: The variation of gain with respect to frequency for various aperture depth $(D)$ values (simulation only).

parameter affecting the antenna gain. The gain values have been examined by using CST STUDIO SUITE EM simulation software. The simulation results (Figure 2) showed that the antenna gain was decreasing especially for the band above 4.0 $\mathrm{GHz}$ and the radiation pattern was deforming as the antenna aperture depth shortened. As a result, an antenna structure with aperture depth $D=5 \mathrm{~cm}$ is decided as optimal by taking into consideration the fact that it was aimed to be constructed as compact as possible.

It is placed in a surrounding box made of PEC material to reduce the undesired side lobes and to obtain a more directive radiation pattern. It would also help to obtain physical protection and EM shielding in a possible application like wireless communication system to overcome the coupling affects between the transmit/receive antennas [8]. The final design of the VS-PDL TEM horn antenna with its dimensions 
TABLE 1: Frequency bands of some of the popular wireless communication systems.

\begin{tabular}{|c|c|c|c|c|c|c|}
\hline $\begin{array}{l}806-960 \mathrm{MHz}, \\
1,710-2,025 \mathrm{MHz} \text {, } \\
2,110-2,200 \mathrm{MHz} \text {, and } \\
2,500-2,690 \mathrm{MHz} . \\
\text { (ITU-R approved } \\
\text { bands) }\end{array}$ & $\begin{array}{c}1.227- \\
1.575 \mathrm{GHz}\end{array}$ & $2.3 \mathrm{GHz}$ & $2.4 \mathrm{GHz}$ & $\begin{array}{c}868 \mathrm{MHz}, \\
915 \mathrm{MHz} \text {, and } \\
2.4 \mathrm{GHz}\end{array}$ & $3.1-10.6 \mathrm{GHz}$ & $\begin{array}{l}900 \mathrm{MHz}, \\
1.8 \mathrm{GHz}, \\
2.4 \mathrm{GHz} \text {, and } \\
5.8 \mathrm{GHz}\end{array}$ \\
\hline $\begin{array}{l}\text { Cellular Phone } \\
\text { Operations (GSM } 3 G \\
\text { and } 4 G \\
\text { (WiMax/LTE)) }\end{array}$ & $\begin{array}{c}\text { Global } \\
\text { positioning } \\
\text { system-GPS }\end{array}$ & Satellite radio & $\begin{array}{l}\mathrm{WiFi} / 802.11 \mathrm{~b} / \mathrm{g} \\
\text { and Bluetooth }\end{array}$ & Zigbee/802.15.4 & UWB & $\begin{array}{l}\text { ISM (Industrial, } \\
\text { scientific, } \\
\text { medical) }\end{array}$ \\
\hline
\end{tabular}

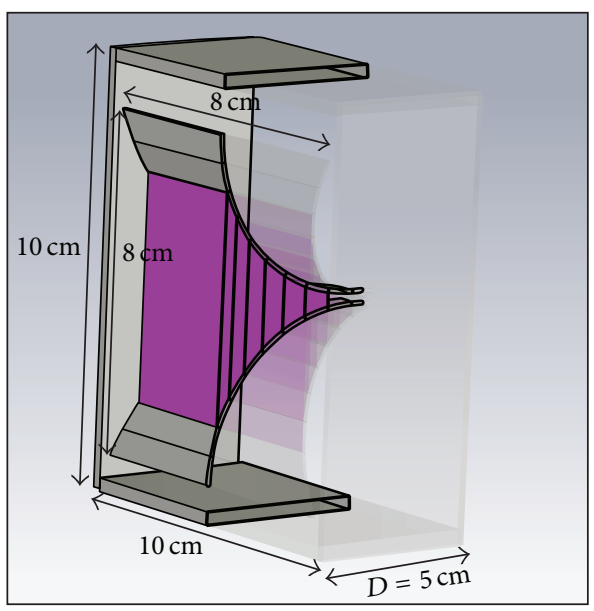

(a)

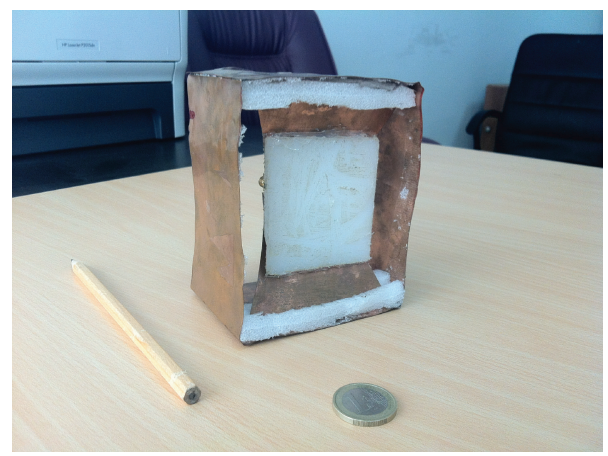

(b)

FIGURE 3: (a) VS-PDL TEM horn antenna design with its dimensions given on the figure. (b) The manufactured antenna.

is given in Figure 3(a) as vertically divided right-handside made transparent for the purpose of clarity while the manufactured antenna is shown in the Figure 3(b).

\section{The Simulation and Actual Measurement Results}

The simulation results show that the Vivaldi shaped partially dielectric loaded (VS-PDL) TEM horn antenna with $5 \mathrm{~cm}$ aperture depth as given in Figure 3(a) achieves an optimum performance over the desired bandwidth while it is practically possible to implement it physically as a compact structure.

The simulated radiation patterns of the VS-PDL TEM horn antenna at selected frequencies within the $1.5-10.6 \mathrm{GHz}$ band for "boxed" and "unboxed" configurations are given in Figure 4 where the bolder line is for the "boxed" configuration.

It can easily be noticed from this figure that, with the metallic box, the radiation pattern becomes more directive especially at the higher frequencies. It offers superior gain performance starting from lower frequencies. The measured radiation patterns of the manufactured antenna verify the simulation results as shown in Figure 5.

The simulated and measured gain values for the antenna are given in Figure 6 while the simulated and measured VSWR plots are given in Figure 7. The measured gain of the antenna remains above $7 \mathrm{dBi}$ over the practical band which is considered as a satisfactory gain performance.

Regarding the VSWR measurements, it remains below 2.0 throughout the operational band until $9.8 \mathrm{GHz}$ but it exceeds that value for the rest of the band which can be considered as not satisfactory. On the other hand, as it does not impact the gain and radiation performance in a negative manner, it can still be considered as practically acceptable. It is also noteworthy to state that for "boxed" configuration, the box itself has a negative effect on VSWR performance at lower part of the bandwidth (1.5 to $2.5 \mathrm{GHz}$ ) resulting a higher VSWR values when compared to "unboxed" case but still the 

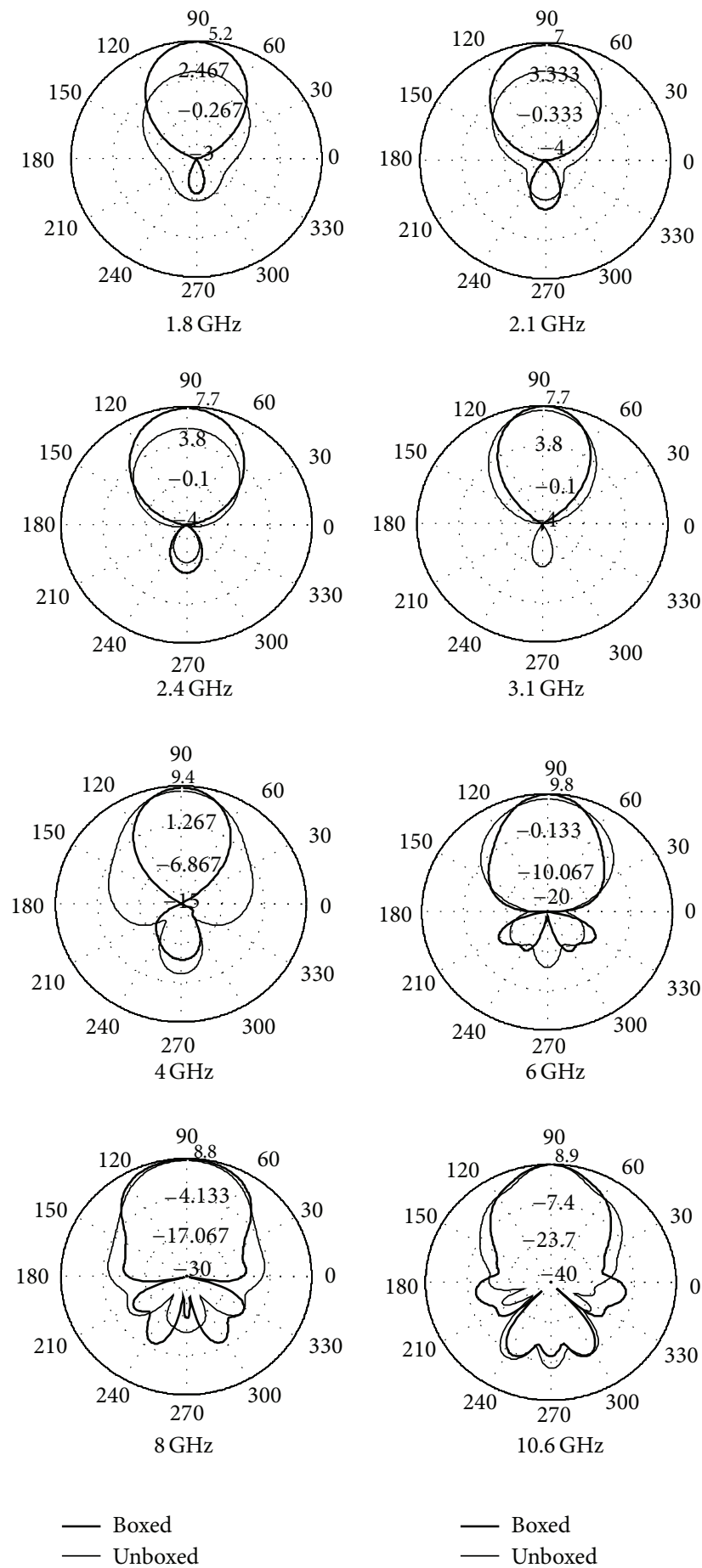

FIgURE 4: The simulated radiation patterns of the VS-PDL TEM horn antenna for "boxed" and "unboxed" configurations at various frequencies.

"boxed" antenna has a satisfactory performance with VSWR values below 2 .

Figure 8 gives the time-domain characteristic of the proposed antenna for the measured received pulse case at various angles for $1.5-11.0 \mathrm{GHz}$. It denotes a smooth pulse
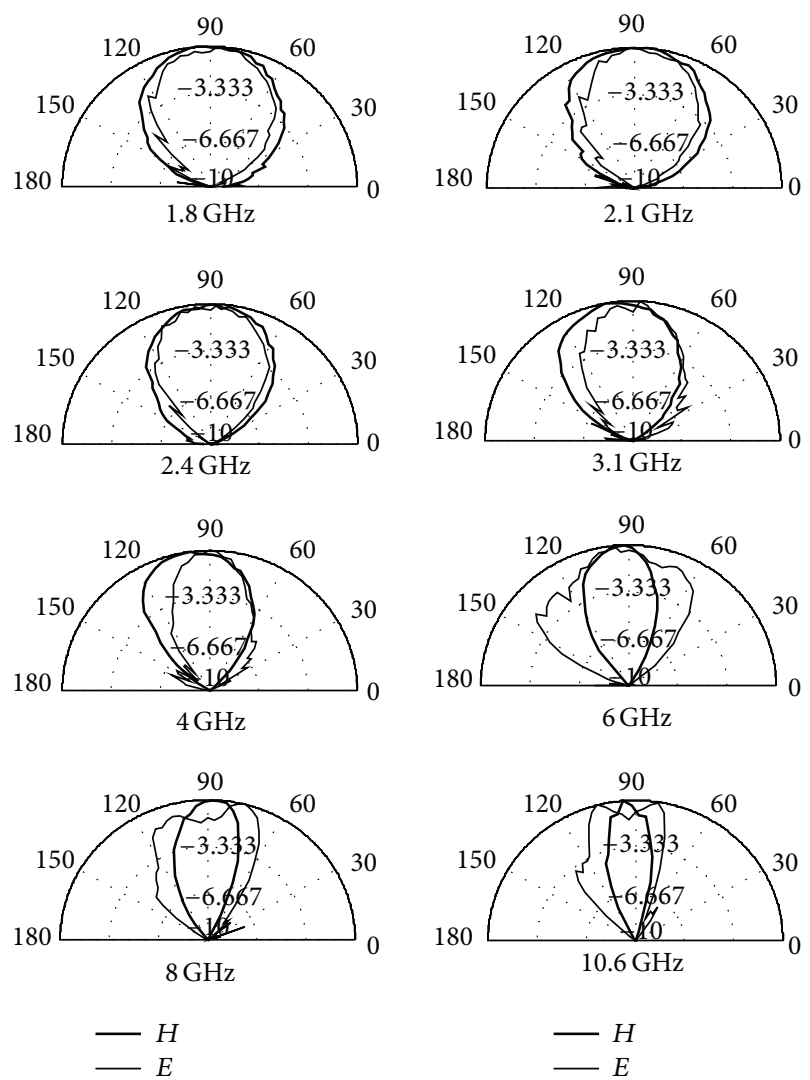

Figure 5: Measured $E$-plane and $H$-Plane (normalized) radiation patterns of the proposed antenna.

shape with minimal ringing effects. The excitation pulse also is plotted within the Figure 8 .

If one evaluates the overall measured performance of the proposed antenna, one can easily conclude that it satisfies the requirements of a multitude of applications ranging from UWB communication to electromagnetic compatibility (EMC) measurement systems in terms of gain, VSWR, and radiation performance due to its reduced size and shielded metallic box structure. Hence it can be considered as a good candidate for popular communication systems like cellular phone, SATCOM, Wi-Fi, Wi-Max/LTE, and other systems using ISM and UWB (Table 1).

\section{Conclusion}

In this paper, a novel compact Vivaldi shaped partially dielectric loaded (VS-PDL) TEM horn antenna has been designed and developed for UWB communication systems of $1.5-10.6 \mathrm{GHz}$ frequency band. We have shown that a new panel type quasiplanar design obtained by more bending the tapered Vivaldi shaped wings (shortened aperture depth) of the TEM horn antenna leads to a significant size reduction of the device. Furthermore, simulation and measurement results that were in coincidence showed that, when installed 


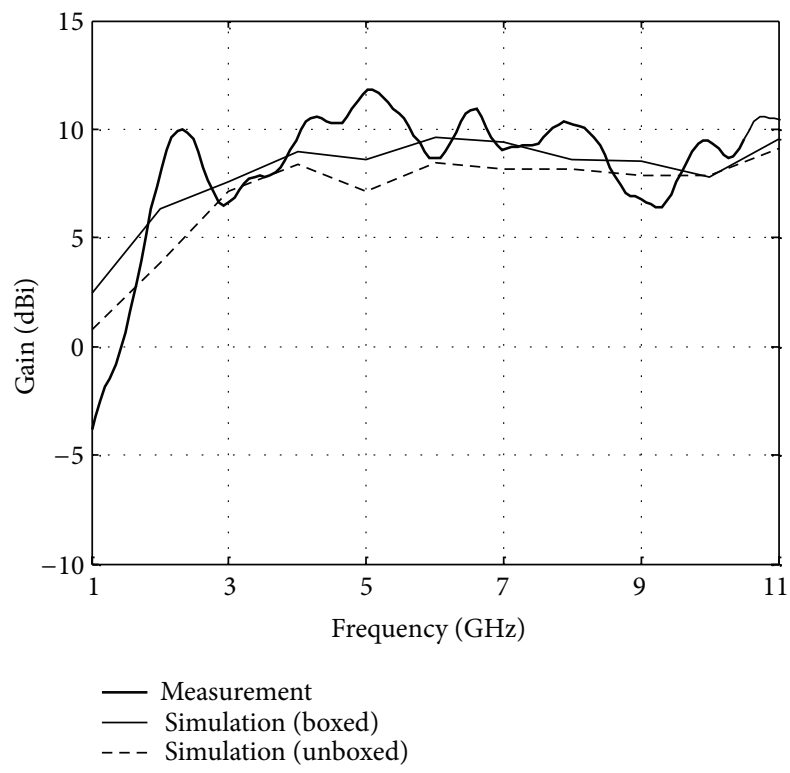

FIGURE 6: Gain performance of the antenna for simulation (both boxed and unboxed) and actual measurement cases.

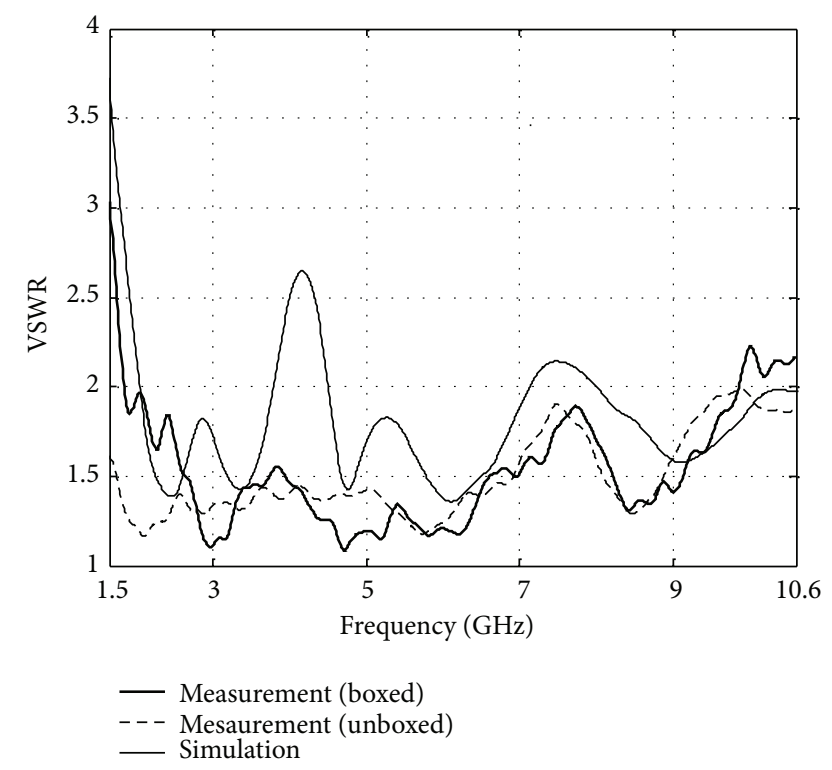

Figure 7: Simulated and measured (for both boxed and unboxed cases) VSWR plot of the antenna.

within a metallic box, VS-PDL TEM horn antenna with a $5 \mathrm{~cm}$ aperture depth has satisfactory far-field radiation characteristics and high gain/lower VSWR over the practical bandwidth. That means such a panel type quasiplanar antenna would be a good candidate for UWB applications like popular communication systems of GSM, GPS, ISM, $\mathrm{Wi}-\mathrm{Fi}$, and SATCOM bands requiring satisfactory antenna performance.

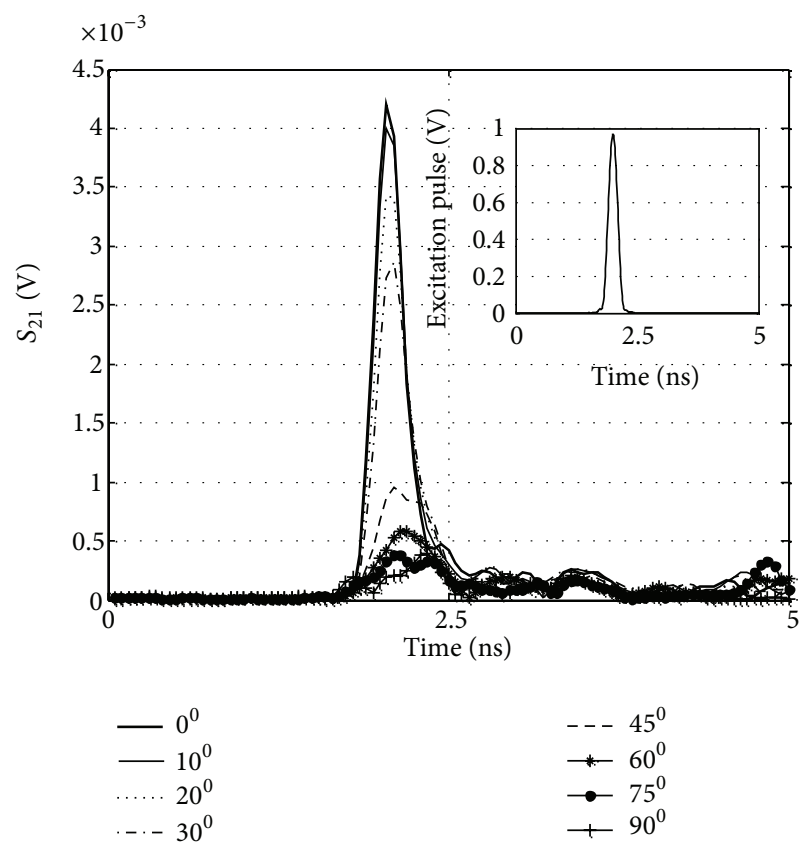

FIGURE 8: Time-domain characteristic of the proposed antenna measured on received pulse for various angles and for 1.5-11.0 GHz. The excitation pulse is given within the figure as well.

\section{Conflict of Interests}

The authors declare that there is no conflict of interests regarding the publication of this paper.

\section{References}

[1] T. Zwick, W. Wiesbeck, J. Timmermann, and G. Adamiuk, Eds., Ultra-Wideband RF System Engineering, EuMA High Frequency Technologies Series, Cambridge University Press, 2013.

[2] A. S. Turk and A. K. Keskin, "Vivaldi shaped TEM horn fed ridged horn antenna design for UWB GPR systems," in Proceedings of the 6th International Workshop on Advanced Ground Penetrating Radar (IWAGPR '11), pp. 1-4, June 2011.

[3] A. Teggatz, A. Jöstingmeier, and A. S. Omar, A New TEM Double-ridged Horn Antenna for Ground Penetrating Radar Applications. Presented at unknown, 2004, http://duepublico .uni-duisburg-essen.de/servlets/DerivateServlet/Derivate-14694/ Final_Papers/GM0023-F.pdf.

[4] A. S. Turk and D. A. Sahinkaya, "Partial dielectric loaded TEM horn design for ultra-wideband ground penetrating impulse radar systems," in Ultra-Wideband, Short-Pulse Electromagnetics 7, chapter 34, pp. 306-315, Springer, Berlin, Germany, 2007.

[5] M. Scheers and A. Acheroy, "Time-domain simulation and characterisation of TEM horns using a normalised impulse response," IEE Proceedings: Microwaves, Antennas and Propagation, vol. 147, no. 6, pp. 463-468, 2000.

[6] A. G. Yarovoy, A. D. Schukin, I. V. Kaploun, and L. P. Ligthart, "The dielectric wedge antenna," IEEE Transactions on Antennas and Propagation, vol. 50, no. 10, pp. 1460-1472, 2002. 
[7] A. S. Turk, "Ultra-wideband vivaldi antenna design for multisensor adaptive ground-penetrating impulse radar," Microwave and Optical Technology Letters, vol. 48, no. 5, pp. 834-839, 2006.

[8] A. S. Turk, D. A. Sahinkaya, M. Sezgin, and H. Nazli, "Investigation of convenient antenna designs for ultra-wide band GPR systems," in Proceedings of the 4th International Workshop on Advanced Ground Penetrating Radar (IWAGPR '07), pp. 192196, June 2007. 

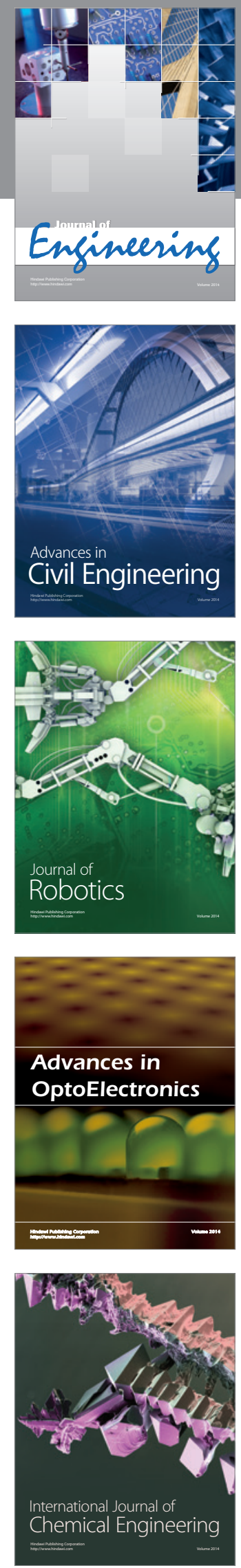

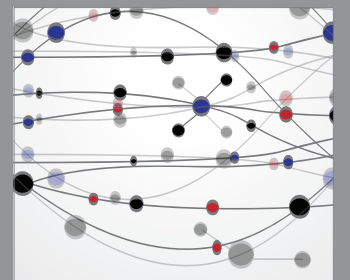

The Scientific World Journal
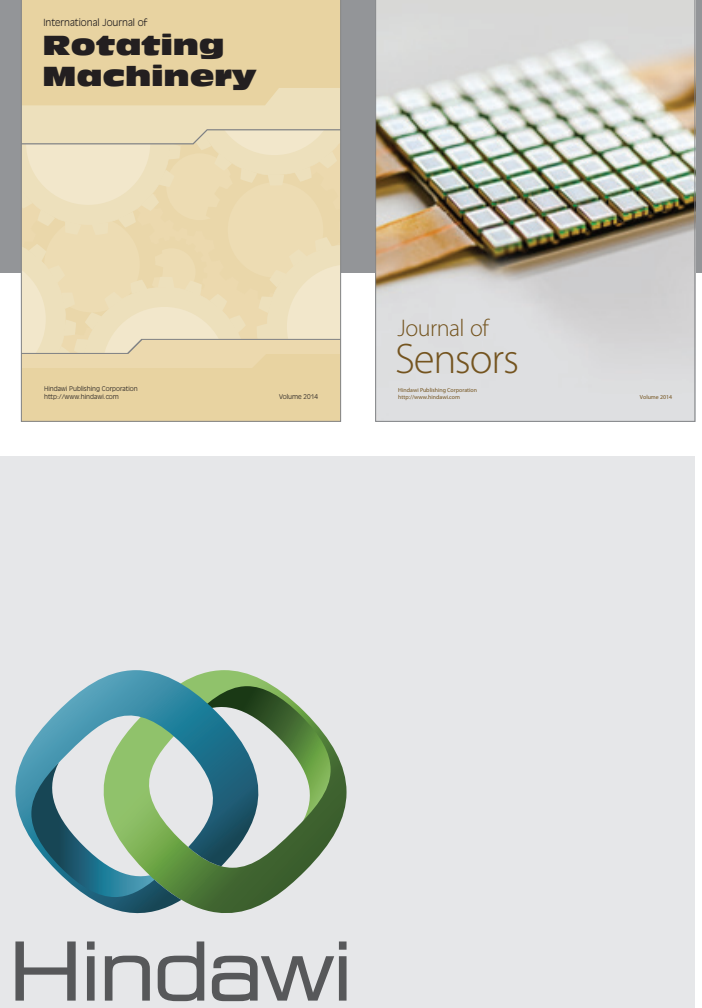

Submit your manuscripts at http://www.hindawi.com
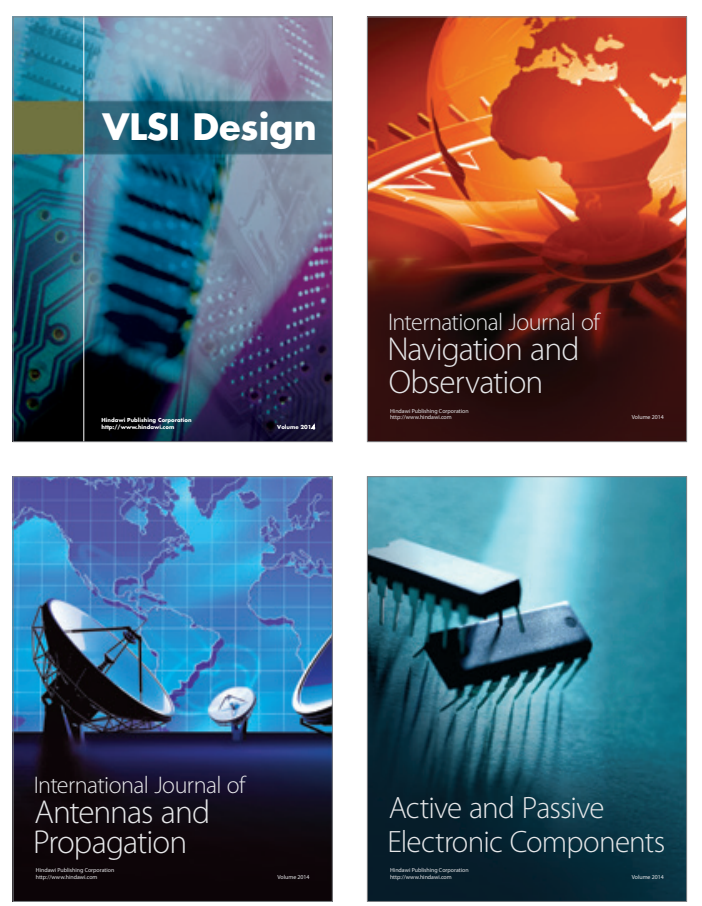
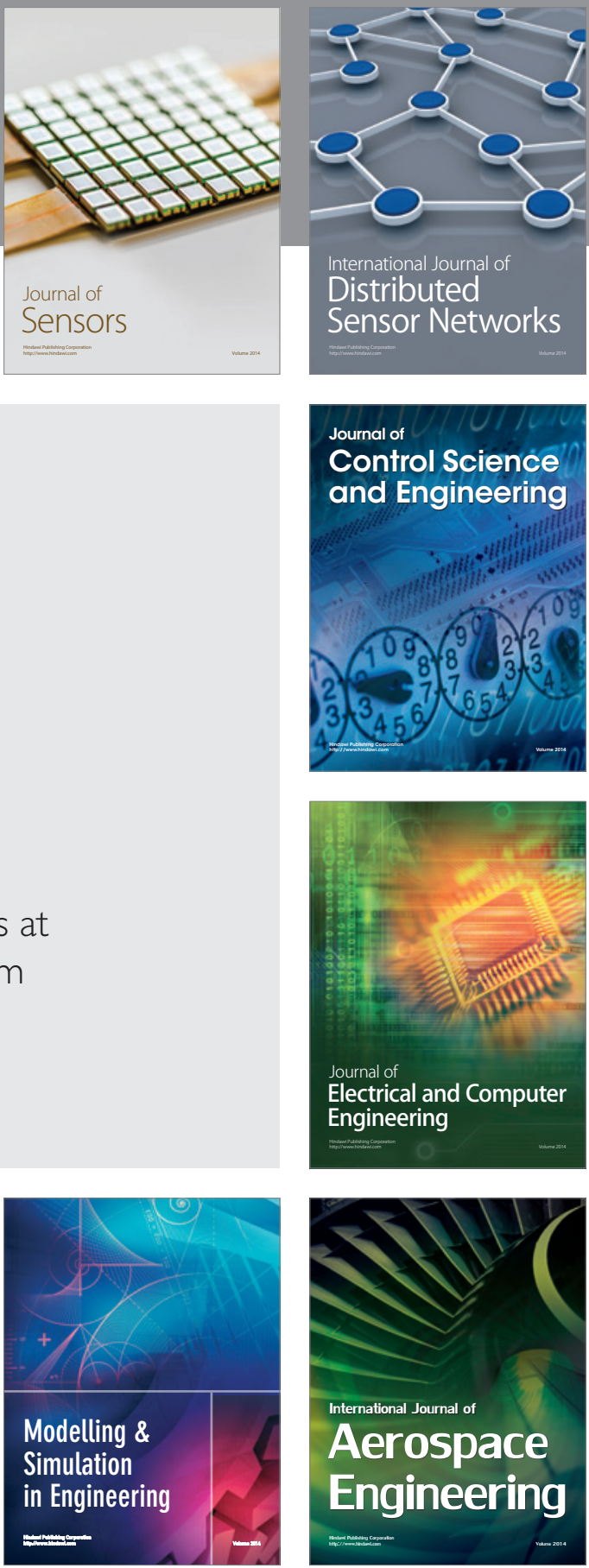

Journal of

Control Science

and Engineering
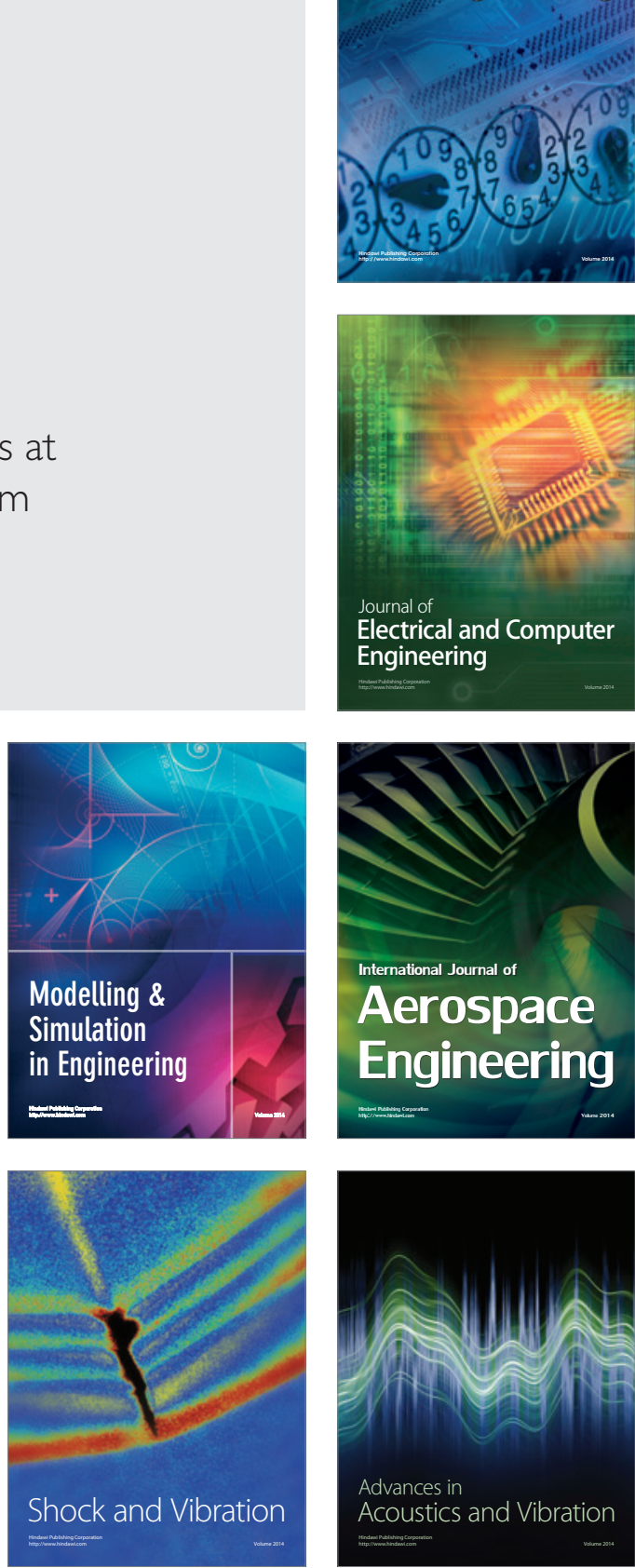